\author{
by Guido R. Zanni, Ph.D.
}

B ehavioral health care refers to the diagnosis and treatment of mental illness and substance abuse. Mental illness is more prevalent and debilitating than substance abuse and is more common than heart disease, cancer, or diabetes. 'The prevalence of mental disorders is staggering:

- One in four Americans suffers from a serious mental illness in their lifetime.

- Two million Americans suffer from schizophrenia, with 300,000 new cases each year. ${ }^{2}$

- Eight million to 14 million Americans suffer from depression each year, with suicide being the third leading cause of death for people between the ages of 1.5 and $24 .^{2}$

- Twenty-eight million adults abuse alcohol or drugs. ${ }^{2}$

Among adults, the five most prevalent conditions are: affective disorders including depression; alcohol abuse and other forms of chemical dependency; anxiety disorders; phobias; and disorders involving severe cognitive impairment. ${ }^{3}$ Many people have more than one of these conditions. Collectively, all office visits for mental disorders involved 81 million pharmacologic interventions. ${ }^{+}$ With 51 million Americans suffering from mental illness in a single year, it is the leading cause of hospital admissions; $21 \%$ of all hospital beds are occupied by patients suffering from mental illness.'

\section{Treatment of Schizophrenia}

Unquestionably, the most debilitating mental illness is schizophrenia. With typical onset in adolescence or early adulthood, prognosis for full recovery is poor and the duration of the illness is frequently measured in decades, if not a lifetime. Treatment has focused primarily on management of its most serious symptoms: delusions and hallucinations. While electroconvulsive therapy, introduced in 1938, provided some level of disease management, real optimism only occurred in 1954 with the introduction of the phenothiazines.

These drugs, along with increased understanding of the biological basis of mental illness, gave millions hope that their level of functioning could improve and confinement to institutional settings might be minimized. Unfortunately, early optimism gave way to the limitations of the phenothiazines. While they controlled hallucinations and delusions, they did little to improve cognitive and social deficits associated with schizophrenia. ${ }^{5}$ Ultimately, long-term use often led to extrapyramidal side effects, including involuntary movements and tardive dyskinesia.

In 1990, optimism soared with the introduction of the atypical antipsychotics. They were thus named because their clinical pharmacology differed significantly from their predecessors. Their clinical properties were more selective for the limbic and cortical regions of the brain and they appeared to be effective even for the most refractory patients. ${ }^{5}$

Clozapine was the first FDA-approved drug in this new class. It was hailed as the most significant advancement for the treatment of schizophrenia since the introduction of chlorpromazine in 1954. Furthermore, some researchers hypothesized that over a period of time, it would improve the social and cognitive deficits that were largely unaffected by the phenothiazines. Unfortunately, optimism was mitigated by clozapine's propensity to induce agranulocytosis in $1 \%$ of treated patients. ${ }^{5}$

Four years later, risperidone was approved, quickly followed by olanzapine and quetiapine. These newer atypicals manifested benelits similar to clozapine, but without inducing agranulocytosis. It has since been discovered, however, that all of the atypicals promote

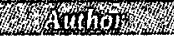

AUTHOR: GUIDO R. ZANNI, PH.D., Health Systems Specialist, Commission on Mental Health Services, Washington, DC. Views expressed are solely those of the author and not those of the Commission on Mental Health Services. 
weight gain and have unique and not necessarily benign side-effect profiles. ${ }^{6}$ Despite their side effects, there is widespread speculation that if a typical antipsychotics are prescribed at the onset of the illness, long-term outcomes may be better. Table l. summarizes the milestones for the treatment of schizophrenia.

Collectively, atypicals improve functioning with fewer side effects. While initially reserved for refractory patients, practice guidelines are rapidly recommending them as first-line treatment. With increasing demand for atypicals, many systems are experiencing budget stress. Table 2 illustrates that these medications are up to 300 times more expensive than traditional neuroleptics.

\section{Cost of Treatment}

Given the prevalence of mental illness, soaring treatment costs are not surprising. The combined annual costs for medical treatment and support for mental illness and substance abuse, along with the associated indirect costs (unemployment, crime, and dependency upon social programs), are estimated to be more than $\$ 273$ billion a year. ${ }^{2}$

In 1996, national health expenditures totaled $\$ 1.03$ billion and represented $13.6 \%$ of the gross domestic product. ${ }^{7}$ The estimated pharmaceuticals' share of total health care expenditures is $7.8 \%$; approximately $\$ 80.7$ million is spent on prescription and nonprescription medications. ${ }^{.}$On a per capita basis, annual expenditure for all medications is $\$ 319$ dollars or 87 cents per day. For prescription drugs only, the annual per capita expenditure is $\$ 233$ dollars or 64 cents per day. ${ }^{9}$ Consider pharmaceutical expenditures in context with others: Daily per capita expenditure for tobacco is 53 cents and for alcohol 91 cents."

Direct expenditures for mental health totaled $\$ 33.136$ billion in 1994 with an annual per capita of $\$ 128$ dollars or 35 cents per day. ${ }^{10}$ Since 1.975 , total mental health expenditures have increased by over $500 \%$, from $\$ 6.564$ billion with an annual per capita of $\$ 31$ dollars or 8.5 cents per day ${ }^{10}$ (see Table 3 ).

Furthermore, treatment of schizophrenia consumes $2.5 \%$ of all health care expenditures." While total medication costs for the treatment of mental illness are lacking, some estimates suggest that $2 \%$ to $5 \%$ of all mental health expenditures is for medications. ${ }^{11,12}$ With the introduction of atypicals, these costs may climb as high as $1.0 \%$. Projecting costs using 1.994 mental health expenditures of $\$ 33.136$ billion, pharmaceutical costs alone may soon exceed $\$ 3$ billion. This projection is not surprising in light of the costs associated with the atypicals and the fact that some insurers report $16 \%$ to $17 \%$ annual price increases for prescription drugs. ${ }^{13}$

\section{Managed Dollars and Care}

While most managed care plans made provisions for behavioral health care, including substance abuse treatment, they did so using carve-out models

\section{TABLE 1- Milestones in Behavioral Health Treatments}

$\begin{array}{ll}1938 & \text { Electroconvulsive therapy } \\ 1954 & \text { Chlorpromazine (Thorazine) } \\ 1958 & \text { Other phenothiazines } \\ 1967 & \text { Thiothixene (Navane) and haloperidol (Haldol) } \\ 1975 & \text { Molindone (Moban) } \\ 1987 & \text { Selective serotonin reuptake inhibitors such as fluoxetine (Prozac) } \\ 1990 & \text { Clozapine (Clozaril) } \\ 1994 & \text { Risperidone (Risperidol) } \\ 1996 & \text { Olanzapine (Zyprexa) } \\ 1997 & \text { Quetiapine (Seroquel) }\end{array}$

\section{TABLE 2}

Cost of Atypicals

Compared With Haloperidol

\begin{tabular}{lll}
\hline Drug & Dose $(\mathrm{mg})$ & Cost/Day $(\$)$ \\
\hline
\end{tabular}

\begin{tabular}{lcc}
\hline Haloperidol & 10 & .04 \\
\hline Clozapine & 400 & 13.68 \\
\hline Risperidone & 5 & 7.10 \\
\hline Olanzapine & 10 & 7.74 \\
\hline Quetiapine & 300 & 6.55 \\
\hline
\end{tabular}

Source: Buckley et al.

where these services were covered outside the health care plan. Referral and payment were under special provisions. Generally, availability and coverage were limited to short-term treatment. In an attempt to control costs, evidence exists that many companies reduced the availability of these services more severely than other types of care..$^{1+}$

Treatment of long-term mental illness was generally not covered by managed care plans and continued to be the responsibility of the public sector. Public providers, however, were not immune from pressure to control costs and the last 10 years have witnessed the rapid growth of managed care in the public sector for a variely of psychiatric conditions. As state Medicaid programs enrolled clients in prepaid health care plans, behavioral health organizations struggled to determine needs, assess financial risks, and understand treatment outcomes. An information void existed for newly covered populations that historically were ignored by the private sector. Pharmacy could no longer be viewed as a cost center with stable and predictable trends.

Cost controls have not been without criticism. Consumer advocacy groups and professional associations have vocalized opposition to what they perceived as rigidly enforced managed care guidelines; guidelines that they maintained limited the decision-making of the individual provider. Allegations were made that private payors were managing profits

Continued on page 15 
Mental Health Costs: 1975 and 1994

\begin{tabular}{c|c|c|c}
\hline Year & Total Expenditures & Annual Per Capita & Capita/Day \\
\hline 1975 & $\$ 6.564$ billion & $\$ 31.00$ & $\$ .085$ \\
\hline 1994 & $\$ 33.136$ billion & $\$ 128.00$ & $\$ .35$ \\
\hline
\end{tabular}

Source: National Center for Heallh Statistics

Continued from page 12

and not care. Furthermore, mental health advocates pointed out that placing limits on the availability of behavioral health care was short-sighted even from a business perspective, as there was a direct relationship between productivity and mental health.

These criticisms had positive effects, bringing treatment outcomes to the forefront of the debate on managed care. The emphasis on quality improvement and treatment outcomes represents the second wave of managed care; services must be delivered in a cost-efficient manner that results in positive outcomes. Emphasizing outcomes has resulted in the application of social science methodology in evaluating the relationship between costs and outcomes. Cost-effectiveness, cost-benefit, and cost-utility principles are being applied with increasing frequency in the design of evaluation models for managed care plans. ${ }^{15}$

\section{The Importance of}

\section{Pharmacoeconomics}

Pharmacy has not been isolated from the debate on treatment costs and outcomes. On the contrary, partly because of this debate, the profession has witnessed the growth of a new specialty-pharmacoeconomics. Pharmacoeconomics employs economic and research techniques and analyzes the relationships between drug therapies and treatment outcomes and costs. ${ }^{16}$

Two recent studies have emphasized behavioral health pharmacoeconomics. Palmer and associates developed a model to test the cost effectiveness of haloperidol, olanzapine, and risperidone in the treatment of schizophrenia. ${ }^{17}$ Their findings indicated that the estimated medical costs over a five-year period for olanzap- ine were $\$ 1,593$ less than those associated with haloperidol, and $\$ 1,875$ less than those associated with risperidone. Patients on olanzapine had an additional 6.8 months in a disability-free state compared to those on haloperidol therapy and 1.6 weeks in a disability-free state compared with those on risperidone treatment. These findings suggest that despite the higher costs associated with the atypicals, total treatment costs decrease, with a corresponding increase in positive treatment outcomes.

Nightengale and associates followed a group of 30 patients treated with risperidone for a minimum of six months; these were matched with 30 patients treated with haloperidol. ${ }^{18}$ Findings revealed that the risperidone group had lower inpatient hospitalization and higher outpatient utilization than the haloperidol cohort. Treatment costs between the two groups did not differ.

These studies employed different methodological assumptions in computing costs and measuring utilization so it is difficult to interpret the conflicting findings on treatment costs.

Nevertheless, these studies represent a rapidly growing literature on the efficacy of behavioral health drug interventions.

\section{Need For Practice Guidelines}

The emphasis on cost effectiveness, treatment outcomes, and pharmacoeconomics has heightened demand for practice guidelines and empirical data demonstrating the relationship between guidelines and outcomes. Understanding these relationships is frequently difficult. One practitioner, Joseph Mack, Pharm.D, M.B.A., vice president of pharmacy services, Magellan Behavioral Health, Columbia, Maryland, observes, "In behavioral health, we don't deal with simple questions such as, "Will this antibiotic kill this species of microorganism?' The questions are far more complex. 'Will this medication lead to an improved quality of life?' Despite the problems of working with soft data, our goal is always to find the right dose at the right time that is safe, clinically effective, and cost efficient."

Unfortunately, development of practice guidelines for behavioral health has been slow in comparison to other disease entities. While this may be due in part to the lack of consensus regarding the treatment of mental illness, there is evidence suggesting that practitioners do not always have access to or make use of existing knowledge. For example, one report suggests that only $29 \%$ of individuals suffering from schizophrenia receive the appropriate dosage of antipsychotic medication over the long term. ${ }^{19}$

The absence of practice guidelines for mental illness results in negative consequences. With limited pharmacy budgets, some states have placed constraints on the use of atypicals. Without clear practice guidelines or treatment hierarchies, patients who could benefit from the atypicals may not be receiving them. Also, some physicians use atypicals and traditional neuroleptics concurrently. Practice guidelines must describe the circumstances under which this is warranted. This practice not only may waste dollars, but presents serious risk management issues. Overall, practice guidelines improve care and ensure appropriate allocation of resources.

\section{Implications For Managed Care Pharmacy}

The need for practice guidelines and the emphasis on pharmacoeconomics have profound implications for managed care pharmacy. First and foremost, financial analysts, risk managers, and members of PET committees are turning to pharmacists to arbitrate debates involving costs and outcomes. In providing consultation on the cost effectiveness of drug therapies, pharmacists must vigilantly identify ethical issues that are disguised as clinical practice issues. For example, if a 
pharmacist is asked to develop a protocol for a new medication as an attempt to reduce its use, this is more an ethical than a practice issue.

Because pharmacy is no longer viewed as a stable cost center with predictable trends, pharmacists will be asked to estimate patient volume by medication class. This is particularly true for the expensive atypicals. Unfortunately, managed care pharmacists will not have the benefit of forecast models. "Unlike other disease entities, it's difficult to predict drug use for behavioral health interventions. This is due in part to the absence of practice guidelines and in part to the general nature of many diagnostic categories. Four people who are diagnosed with schizophrenia will frequently have four different drug regimens which frequently include classes of various antipsychotics," according to Jeannette Y. Wick, R.Ph., director of pharmacy in Maryland, a state that is in the process of adopting managed care principles.

The second implication is the need for managed care pharmacists to go beyond simply keeping abreast of relevant literature. Individual studies as well as collective findings of all studies must be critically evaluated. Because pharmacists will be consulted on pharmacotherapy and outcomes, it is crucial that they understand basic research and statistical principles. Without this knowledge, their consultation will be limited

In evaluating individual studies, numerous questions must be raised about adequate sample sizes for conclusions, assumptions regarding disease progression and service utilization, research funding, age or gender restrictions placed on the cohort under consideration, and employment of valid outcome measures. For example, does lack of hospitalization always translate into improved quality of life? Also, were there hidden costs associated with treatment? This latter point is critical since people suffering from mental illness require a host of costly, nonmedical community supports.

Managed care pharmacists also must evaluate the literature as a whole. Separate studies investigating the same question frequently reveal conflicting findings. If there is conflicting literature on the efficacy of a particular treatment, a true understanding is obviously lacking. Factors linking interventions and outcomes are exceedingly complex, and years of research are required to fully understand the relationship. "Practitioners will turn to pharmacists for answers to questions regarding therapeutic ranges and outcomes. Pharmacists must be prepared to objectively evaluate the material they read," says Dr. Mack.

There is a major role for managed care pharmacists in practice guideline development. In the absence of research data, decisions and value judgments are needed. For example, should the newer atypicals be used as first-line treatment? There is speculation that their use may alter some of the most severe social and cognitive effects. Despite the limited availability of data on potential long-term negative effects of these medications, managed care pharmacists must be prepared to evaluate the risks and benefits.

Finally, practice issues overlap consumer preferences. Consumers have quickly become aware of the benefits of the atypicals and are demanding unrestricted access. These requests must balance budgetary issues with practice guidelines that may suggest a treatment hierarchy in which atypicals are not firstline treatment. Consumer preferences, risks, benefits, and the medical necessity of the pharmacotherapy must be balanced. As pharmacoeconomic data are utilized in formulary management and recommendations, the pharmacist's role on P\&T committees is rapidly changing to that of practitioner/research analyst.

\section{Summary}

The development of practice guidelines for the treatment of mental illness involves both knowledge of the efficacy of drug therapies and value judgments regarding risks and benefits of treatments. With media attention on mental illness and the requirement for parity coverage, behavioral health care organizations are aggressively rethinking the role of pharmacy. Managed care pharmacists will be consulted with increasing frequency regarding the complex relationships between treatment, outcomes, and costs. This new role advances the profession of pharmacy to the forefront of medical practice, a role that is clearly welcomed and one for which every pharmacist must be prepared.

\section{REFERENCES}

1. Mental Health Information and Statistics. www.mhsource.com/exclusive/mh.

2. ViaHealth Disease and Wellness Information. Mental health disorders. www.viahealth org/disease/mentalhealth/OldMentalHealth/facts.

3. National Alliance for the Mentally 1ll. Statistical prevalence of mental illness. www.schizophrenia.nami.org/helpline/illstats.

4. National Center for Health Statistics.

Ambulatory care visits to physician officers, hospital outpatient departments, and emergency departments: United States, 1996. Series 13, No. 134, February 1998.

5. Lieberman J. Treatment of schizophrenia: trends and outlook. Psychiatric Times, 1995; 7:6.

6. Wirshing D. Antipsychotics differ in weight gain liabilities. J of Clinical Psychiatry 1999; 60: 358-63.

7. National Center for Health Statistics. Health expenditures. www.cdc.gov/nchswww-

/fastats/hexpense.

8. PhRMA Publications. Pharmaceutical industry profile. www.phrma.org/publications/industry/profile99/figures/7-6

9. PhRMA Publications. Pharmaceutical industry profile. www.phrma.org/publications/industry/profile99/figures/4-46.

10. National Center for Health Statistics. Mental health expenditures, percent distribution, and per capita expenditure, by type of organization, select ed years 1975-1994. www.cdc.gov/nchswww/fastats/mental.

11. Buckley P. Treatment of schizophrenia: let's talk dollars and sense. Am J Managed Care 1998; 4 (3): 369-83.

12. Wick J chief of pharmacy, DC Commission on Mental Health Services. Personal communication. 1999.

13. Medicare+Choices: Why have HMOs pulled out? Orphan Disease Update 1999; 8 (2): 4.

14. Mechanic $D$. The state of behavioral health in managed care. Am J of Managed Care 1999; 5 (Special Issue): Sp17-Sp21.

15. Aday L, Begley C, Lairson D, et al. A framework for assessing the effectiveness, efficiency and equity of behavioral health care. Am J of Managed Care 1999; 5 (Special Issue): Sp25-Sp44.

16. Wilson A. Demystifying pharmacoeconomics. Drug Benefit Trends 1999; $11(5)$ : 56-58, 61-62, 67. 17. Palmer C, Revicki D, Genduso L, et al. A costeffectiveness clinical decision analysis model for schizophrenia. Am J of Managed Care 1998; 4(3): 345-55.

18. Nightengale B, Garret 1 , Waugh $\mathrm{S}$, et al. Economic outcomes associated with the use of resperidone in a naturalistic selting. Am J of Managed Care 1998; 4(3): 360-66.

19. Buckley $P$, et al. Implementing effectiveness research and improving care for schizophrenia in real-world settings. Am J Managed Care 1999 5(SP). 